\title{
Morphological and functional alterations in adult boar epididymis: Effects of prenatal and postnatal administration of flutamide
}

Marta Lydka, Ilona Kopera-Sobota, Malgorzata Kotula-Balak, Katarzyna Chojnacka, Dorota Zak, Barbara Bilinska*

\begin{abstract}
Background: The dynamic cross-talk between epididymal cells is hormonally regulated and, in part, through direct cell-to-cell interactions. To date, no information is available regarding possible impact of anti-androgens on the proteins involved in the gap junctional communication within the boar epididymis. Thus, a question arised whether prenatal or postnatal exposure to an anti-androgen flutamide alters the expression of gap junction protein - connexin43 (Cx43) and androgen receptor (AR) expression in the caput, corpus and cauda epididymis and leads to delayed effects on morphology and function of adult pig epididymis.

Methods: First two experimental groups received flutamide prenatally on gestational days 20-28 and 80-88 (GD20 and GD80) and further two groups were exposed to flutamide postanatally on days 2-10 and 90-98 after birth (PD2 and PD90). Epididymides were collected from adult boars. Routine histology was performed using hematoxylineosin staining. The expression of $\mathrm{Cx} 43$ and AR were analyzed using immunohistochemistry and Western blotting. Both analyses were supported by quantitative approaches to demonstrate the variations of the expression levels following the treatment. Apoptotic cells were identified using TUNEL assay.

Results: Histological examination revealed differences in epididymal morphology of flutamide-exposed boars when compared to controls. Scarce spermatic content were seen within the corpus and cauda lumina of GD20, PD2 and PD90 groups. Concomitantly, frequency of epididymal cell apoptosis was significantly higher $(p<0.05)$ after exposure to flutamide at GD20. Moreover, in GD20, PD2, and PD90 groups, significantly lower AR expression ( $p<$ 0.05) was found in the principal and basal cells of the corpus and cauda regions, while in the stromal cells AR expression was significantly reduced $(p<0.05)$ along the epididymal duct. Concomitantly, a decrease in Cx43 expression $(p<0.05)$ was noticed in the stromal cells of the cauda region of GD20 and PD2 groups. This indicates high sensitivity of the stromal cells to androgen withdrawal.

Conclusions: The region-specific alterations in the epididymis morphology and scarce spermatic content within the lumina of the corpus and cauda indicate that flutamide can induce delayed effects on the epididymal function of the adult boar by decrease in AR protein levels that results in altered androgen signaling. This may cause disturbances in androgen-dependent processes including Cx43 (de)regulation, however, we can not exclude the possibility that in response to flutamide decreased Cx43 expression may represent one mechanism responsible for functional disturbance of the boar epididymis.
\end{abstract}

\footnotetext{
* Correspondence: barbara.bilinska@uj.edu.pl

Department of Endocrinology, Institute of Zoology, Jagiellonian University, Krakow, Poland
} 


\section{Background}

The intercellular communication mediated by gap junctions coordinates cellular functions within reproductive tissues and whole organs in a complementary way to other regulation of basic cellular functions [1]. Throughout the length of the ductus epididymis communication systems are based on a secretion of hormones [2]. Their cooperation determines the appropriate luminal microenvironment that is formed for the functional maturation, storage and protection of spermatozoa $[3,4]$. Due to several mechanisms various proteins secreted in the epididymis are highly regionalized and are specific to each region of the adult boar [5]. Although gap junctions between adjacent principal cells of epididymis were identified by freeze fracture electron microscopy almost forty years ago [6] the presence and the physiological role of gap junctions in the processes that involve the final maturation of spermatozoa during their transit along the epididymal duct are largely unknown. Scarce information is also available regarding possible effects of anti-androgens on the integral proteins that build intercellular junctions in the male $[7,8]$.

Since androgens are known to maintain the morphology and secretory function of the epididymis acting directly through androgen receptor (AR) [9-11], the effect of an antiandrogen flutamide, which is known to hinder androgen action by inhibiting receptor binding of androgen is of special interest. It should be mentioned that Pearl et al. [11] demonstrated no change in the concentration of androgens and estrogens throughout the boar epididymis and suggested that regional differences in steroid regulation are likely due to differences in receptor expression. The effects of androgen deprivation induced by orchiectomy, GnRH agonist administration and ethane dimethane sulphonate treatment have been shown in the epididymis of several mammalian species including pigs [12-15]. Recently, changes in the expression of antioxidant enzymes that protect germ cells from damage by various forms of reactive oxygen species have been demonstrated in epididymal epithelial cells of finasteride-treated rats [16]. Androgen receptors have been localized to epididymal cells in humans and several other mammalian species [17-20], however, the effect of flutamide on AR expression has never been investigated in porcine epididymis.

The question arises whether adverse effects of flutamide on epididymal morphology and function can be related either to affected gap junction communication and/or altered expression of the AR.

To show a role of androgens in the modulation of the gap junctional intercellular communication and sensitivity of epididymal cells to androgens, the expression of predominant gap junction protein connexin 43 (Cx43) and the AR were detected in three regions of adult boar epididymis by means of immunohistochemistry and Western blotting. To check whether the effect of flutamide depends on the time of its administration, prenatal and postnatal exposures were applied. It should be added that recently we have demonstrated that exposure to flutamide induced adverse effects on male and female gonad morphology and the expression of $\mathrm{Cx} 43$ protein in gonads of prepubertal pigs [21], not in neonates [22].

\section{Materials and methods}

\section{Animals and experimental design}

Nine-month-old adult boars (Large White $\times$ Polish Landrace) originating from five litters were allotted into four groups of experimental animals $(n=3)$ and respective control groups $(n=3)$. First two experimental groups were exposed prenatally on gestational days 20-28, and 80-88 (GD20 and GD80) to an anti-androgen flutamide (2-methyl-N-[4-nitro-3-(trifluoromethyl)-phenyl]propamide; Sigma-Aldrich, St Louis, MO, USA). Two further groups were treated with flutamide postanatally on days 2-10 and 90-98 after birth (PD2 and PD90). The control animals were given a vehicle only (corn oil). Flutamide was administered at a dose of $50 \mathrm{mg} / \mathrm{kg}$ body weight five times every second day. The flutamide exposure was based on the literature [23] and our own data described in detail previously $[21,22]$.

The epididymides were obtained from 270-day-old animals, irrespective of the time of flutamide treatment. All surgical procedures were performed by a veterinarian and followed approved guidelines for the ethical treatment of animals in accordance with the Polish legal requirements under the licence given by the Local Ethics Committee at the Jagiellonian University, Krakow, Poland (No. 4/2008).

\section{Tissue Preparation}

Every two epididymides of both control and flutamidetreated boars ( $\mathrm{n}=3$ each group) were surgically removed and small fragments of the epididymal tissue were immersed either in Bouin fixative or in $4 \%$ formaldehyde freshly prepared from paraformaldehyde for histology or immunohistochemistry, respectively, and embedded in paraplast (Monoject Scientific Division of Scherwood Medical, St Louis, MO). Sections of $6 \mu \mathrm{m}$ in thickness were mounted on slides coated with 3-aminopropyltriethoxysilane (APES; Sigma-Aldrich Chemical Co., St Louis, MO), deparaffinized and rehydrated. For routine histology haematoxylin-eosin (H-E) staining was performed.

\section{Immunohistochemistry}

To optimize immunohistochemical staining slices were immersed for $2 \times 5 \mathrm{~min}$ in $10 \mathrm{mM}$ citrate buffer 
( $\mathrm{pH}$ 6.0) and heated in the microwave oven (750 W). Details of a whole procedure have been described elsewhere $[24,25]$. Briefly, nonspecific staining was blocked twice, first with $3 \% \mathrm{H}_{2} \mathrm{O}_{2}$ in methanol for $15 \mathrm{~min}$, to inhibit endogenous peroxidase activity, and second with $5 \%$ normal goat serum for $30 \mathrm{~min}$ at room temperature to block nonspecific binding sites. Thereafter, sections were incubated overnight at $4^{\circ} \mathrm{C}$ in a humidified chamber in the presence of polyclonal antibodies against $\mathrm{Cx} 43$ (1:2000; Sigma-Aldrich; St Louis, MO, USA) and AR (1:2000; Santa Cruz Biotechnology, Santa Cruz, CA, USA). Next, biotinylated secondary antibody, goat anti-rabbit IgG (1:400; Vector, Burlingame CA, USA) was applied. Finally, avidin-biotinylated horseradish peroxidase complex (ABC/HRP; 1:100; Dako, Glostrup, Denmark) was used. After each step in these procedures, sections were carefully rinsed with Tris-buffered saline (TBS; $0.05 \mathrm{M}$ Tris- $\mathrm{HCl}$ plus $0.15 \mathrm{M} \mathrm{NaCl}, \mathrm{pH}$ 7.6); the antibody was also diluted in TBS buffer. Bound antibody was visualized with TBS containing $0.05 \%$ 3.3'-diaminobenzidine tetrachloride (DAB), $0.01 \% \mathrm{H}_{2} \mathrm{O}_{2}$ and $0.07 \%$ imidazole for 3-4 $\mathrm{min}$. Counterstaining with Mayer's hematoxylin was additionally performed. In control sections, the primary antibody was replaced by normal goat serum. Then, sections were examined with a Leica DMR microscope (Leica Microsystems, Wetzlar, Germany) using a bright field illumination for morphology and Nomarski interference contrast for immunohistochemistry.

\section{Qualitative and quantitative evaluation of the immunohistochemical reactions}

Immunohistochemical staining for both antigens, $\mathrm{Cx} 43$ and AR, was evaluated qualitatively in at least 20 serial sections of epididymides from each experimental group. The slides were processed immunohistochemically at the same time with the same treatment so that the staining intensities could be compared. The epididymal cells were considered immunopositive if brown reaction product was present in the cell nuclei (AR) or appeared as signal between epididymal cells (Cx43); the cells without any specific immunostaining were considered immunonegative.

To evaluate the intensity of immunohistochemical reaction quantitatively, digital color images were obtained using a CCD Video Camera (KY-F55, JVC) mounted on an optical microscope (Microphot, Nikon, Japan) and connected to a video capture card (PV-BT878P, Prolink, Taiwan) installed on a personal computer. Images of the epididymides were captured using a $20 \times$ objective as described previously [26]. Image processing and analyses were performed using the public domain ImageJ software (National Institute of Health, Bethesda, MD, USA). The intensity of the immunohistochemical reaction was expressed as relative optical density (ROD) of diaminobenzidine brown reaction product and calculated using the formula described by Smolen [27]. A total number of 50 epididymal sections ( $n=10$ per group) were subjected to image analysis and results of 10 separate measurements were expressed as mean $\pm \mathrm{SD}$.

\section{TUNEL assay}

The presence of apoptosis-related DNA strand breaks in epididymal cells was evaluated by TUNEL assay using the In situ Cell Death Detection kit, POD (Roche Molecular Biochemicals, Mannheim, Germany) according to the manufacturer's instructions with our own modifications [28]. In short, after deparaffinization and rehydration, the $6 \mu \mathrm{m}$ paraplast tissue sections were immersed in $3 \% \mathrm{H}_{2} \mathrm{O}_{2}$ to quench endogenous peroxidase activity, rinsed in PBS and incubated with $10 \mu \mathrm{g} / \mathrm{ml}$ Proteinase $\mathrm{K}$ solution (Promega Corporation, Madison, WI, USA) for $15 \mathrm{~min}$ at $37^{\circ} \mathrm{C}$. Thereafter, sections were incubated with TUNEL reaction mixture (terminal deoxynucleotidyl transferase and labeled nucleotide mixture). Next, sections were rinsed in PBS and incubated with Converter-POD (anti-fluorescein antibody conjugated with horse-radish peroxidase). Peroxidase activity was then visualized by precipitation of DAB (DAB Substrate, Roche, Mannheim, Germany). Cells containing fragmented nuclear chromatin exhibited a brown nuclear stain. As negative controls, sections were processed without terminal deoxynucleotidyltransferase (TdT) buffer. Apoptotic cells were examined with Leica DMR microscope. The number of TUNEL-positive cells was noted per 100 cross-sections of epididymal ducts.

\section{Western blot analysis}

Tissues were homogenized on ice with a cold Tris/ EDTA buffer $(50 \mathrm{mmol} / \mathrm{L}$ Tris, $1 \mathrm{mmol} / \mathrm{L}$ EDTA, $\mathrm{pH}$ 7.5 ), sonicated and centrifuged at $10000 \times g$ for $20 \mathrm{~min}$ at $4^{\circ} \mathrm{C}$ as described previously [29]. In short, the protein concentration for each sample was estimated using Bradford dye-binding procedure with BSA as a standard [30]. Homogenates containing $50 \mu \mathrm{g}$ of protein were solubilized in a sample buffer (Bio-Rad Labs, GmbH, München, Germany) and heated at $99.9^{\circ} \mathrm{C}$ for $3 \mathrm{~min}$. After denaturation the samples were subjected to electrophoresis on SDS-PAGE gels ( $8 \%$ and $12 \%, \mathrm{v} / \mathrm{v}$ ) according to Laemmli [31]. Separated proteins were transferred onto a nitrocellulose membrane using a wet blotter in the Genie Transfer buffer ( $\mathrm{pH}$ 8.4) for $90 \mathrm{~min}$ at $250 \mathrm{~mA}$. Then, blots were blocked overnight at $4^{\circ} \mathrm{C}$ with shaking in a solution of non-fat dry milk $(5 \%, \mathrm{w} / \mathrm{v})$ in TBST, followed by incubation with rabbit polyclonal antibodies against Cx43 (1:8000; Sigma-Aldrich) and AR (1:200; Santa Cruz) for $1.5 \mathrm{~h}$ at room temperature. The membranes were washed and incubated with a goat anti-rabbit IgG linked to the horseradish-peroxidase 
(1:1000; Vector Lab.) for $1 \mathrm{~h}$ at room temperature. Then, bound antibody was revealed using 3, 3'diaminobenzidine as the substrate (DAB; $0.5 \mathrm{mg} / \mathrm{mL}$ ). Finally, the membranes were dried and then scanned using Epson Perfection Photo Scanner (Epson Corporation, CA). Molecular masses for the AR and Cx43 were estimated by reference to standard proteins (Fermentas, $\mathrm{GmbH}$, St. Leon-Rot, Germany and Bio-Rad Labs, Inc., CA USA), respectively. For positive controls pig prostate and pig heart were used. To obtain quantitative results, the bands representing each data point were densitometrically scanned using Image LaB ${ }^{\mathrm{TM}} 2.0$ (Bio-Rad Labs). Quantitative analysis was performed for three separately repeated experiments from each control and experimental groups. Protein level within a control group was arbitrarily set as 1, against which statistical significance was analyzed.

\section{Statistical Analysis}

All statistical analyses were performed using one-way analysis of variance (ANOVA) followed by Tukey's post hoc comparison test. The analysis was made using Statgraphics Centurion XV software. Data were presented as mean $\pm \mathrm{SD}$. The significance level was considered to be $p<0.05$.

\section{Results}

\section{Histological examination}

In both flutamide-treated and untreated boars the epididymal epithelium of the caput, corpus and cauda epididymis was composed of two major cell types: principal cells that outnumbered all the other cell types and basal cells. Independently of the group of boars, in the caput and corpus epididymis the principal cells were columnar in shape and became slightly lower in the cauda region (Figure 1A-O). The oval shaped basal cells were found throughout the epididymis besides the initial segment in which only few basal cells were present or they were not present at all (inserts in A, D, G). Spermatozoa were observed in the epididymal lumina of control and experimental groups (Figure 1A-O). In the latter, however, scarce spermatic content were seen in the corpus and cauda of GD20, PD2 and PD90 groups (Figure 1F, $\mathrm{K}-\mathrm{L}, \mathrm{N}-\mathrm{O})$. Concomitantly, the epithelial height of the cauda region increased and the stroma layer enlarged distinctly (Figure 1I, L, O). In the corpus, however, the epithelial heights were reduced (Figures. 1E, H, K, N). Frequently, the caudal epididymal region of GD20 and GD80 groups exhibited less folded appearance (Figure 1F, I), while that of the PD2 and PD90 showed deep invagination of the epididymal epithelium that sporadically led to its closure (Figure 1L, insert in O). In epididymal lumina either cell sloughing was observed (Figure $1 \mathrm{~F}, \mathrm{I}$, insert in I) or bubble-like vesicles of sloughed cytoplasmic membranes were detected (Figure 1L, O). In the cauda of the GD20 group the intra-epithelial lymphocytes were frequently observed (insert in F). Occasionally, likely phagocytic leukocytes, characteristic of an inflammation response to tissue damage were seen either in the lumen or in the stroma of the caput epididymis of postnatally exposed boars (Figure 1J, M, inserts in $\mathrm{J}, \mathrm{M})$.

\section{TUNEL assay}

TUNEL staining was used to quantify apoptosis along the epididymal duct. As a result TUNEL-labeled cells were detected in epididymides of control (Figure 2A-C) and experimental groups, however the most prominent effect of flutamide, manifested by the apparent increase of apoptotic cell number, was noticed in the GD20 group (Figure 2D-F). Apoptotic cells were mostly accounted for as degenerating epithelial cells or germ cells transported from the testes after their degeneration. Microscopic evaluation was confirmed by quantitative analysis of the TUNEL assay that revealed significantly higher frequency of epididymal cell apoptosis $(p<0.01)$ especially in the caput and cauda regions of all groups examined when compared to the control (Figure 2K). In the GD20 group, mean numbers of TUNEL-positive cells per 100 cross-sections of epididymal ducts increased drastically in the caput ( $\sim 9$-fold), in the corpus $(\sim 3$-fold), and in the cauda $(\sim 5$-fold). Negative control sections, processed without TdT buffer, showed no staining (see, insert in Figure 2B).

\section{Qualitative and quantitative evaluation of Cx43 localization and expression}

After flutamide exposure, the pattern of $\mathrm{Cx} 43$ staining was similar to the control, while the intensity of the staining varied in comparison with the control (Figure 3A-O). Irrespectively of the group of boars, very weak signal for $\mathrm{Cx} 43$ or no $\mathrm{Cx} 43$ signal was observed between the basal and principal cells and between the basal and stromal cells of the caput region (Figure 3A, D, G, J, M). Interestingly, in the initial segment an apparent signal for $\mathrm{Cx} 43$ was noticed between neighboring principal cells, especially of GD20 and GD80 groups in comparison to the control (inserts in A, D, G). In the corpus a very weak punctate signal was observed among the basal cells, while it was of moderate intensity between adjacent stromal cells (Figure 3B). Between the latter the signal decreased distinctly in GD20 and PD2 groups (Figure 3E, K). In the cauda of GD20 and PD2 groups a marked decrease in Cx43 immunoreactivity concerned the stromal cells (Figure 3F, L). No positive staining for Cx43 was detected when the primary antibody was omitted (insert in B). Qualitative analysis of Cx43 immunoreactivity (Figure $3 \mathrm{~A}-\mathrm{O}$ ) was confirmed by a 


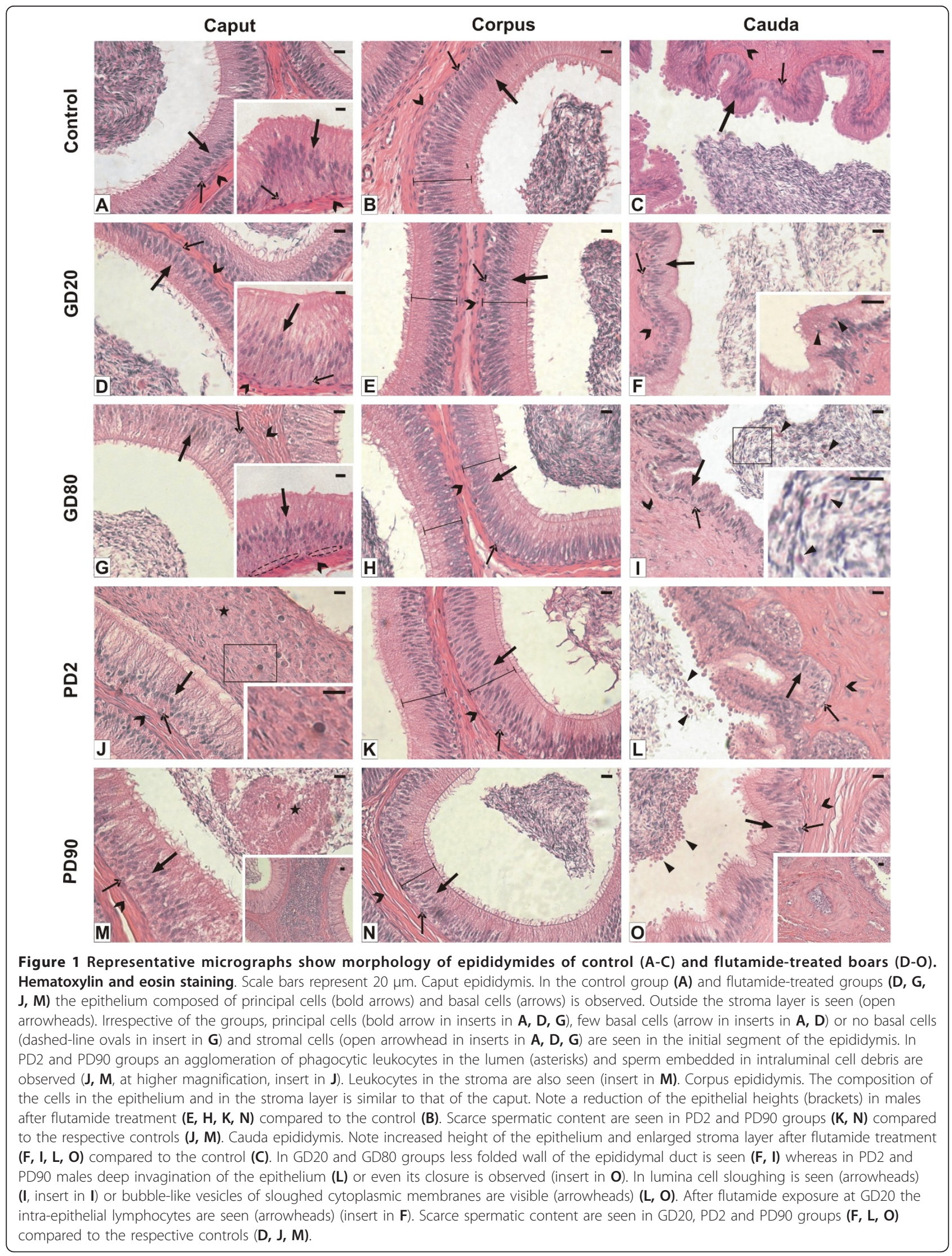



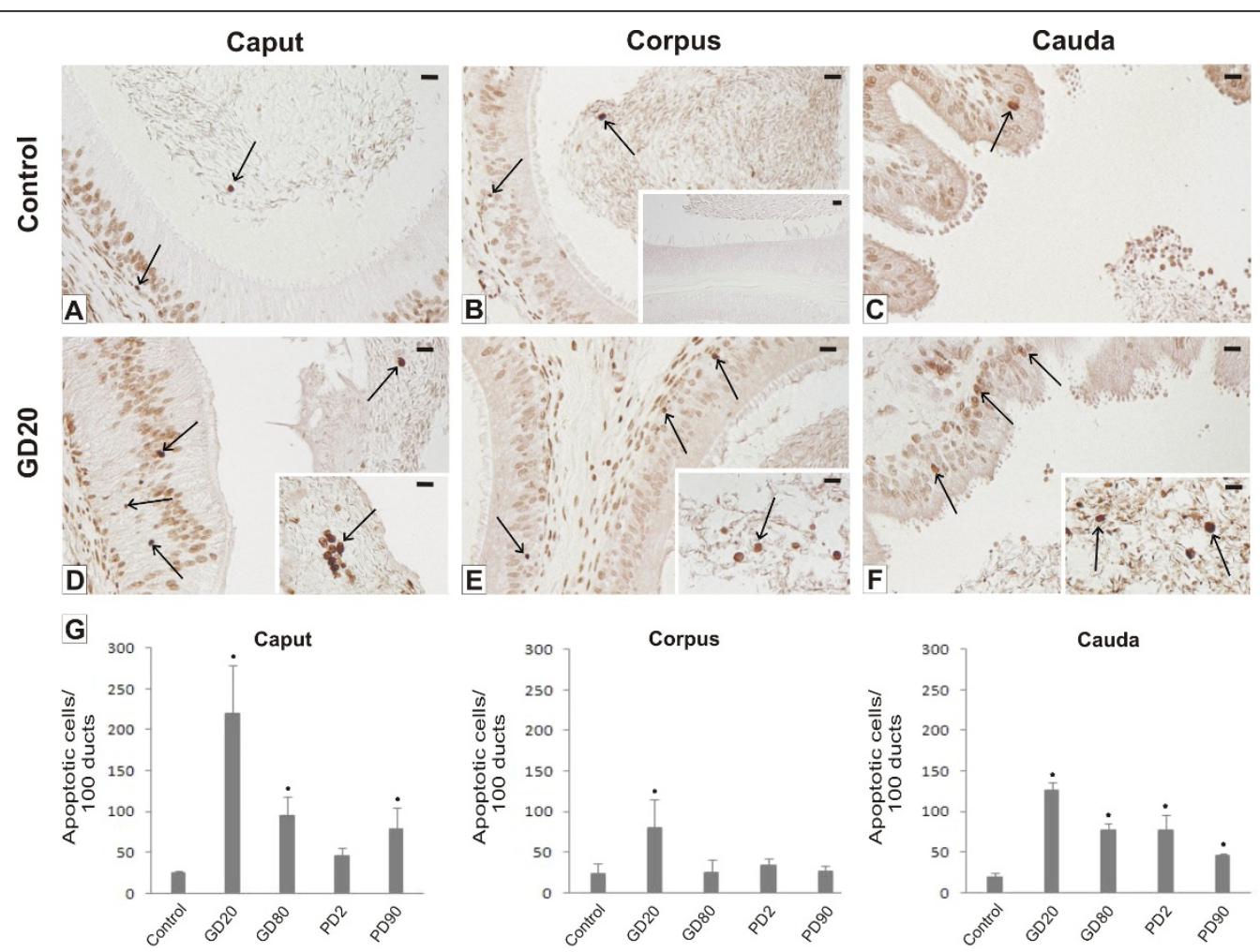

Figure 2 Qualitative and quantitative analysis of apoptotic cells visualized using the in situ death detection kit POD. Representative micrographs (A-F) and a histogram (G) of apoptotic cell number. Note increased number of apoptotic epithelial cells (D-F) and germ cells (inserts in D-F) along the epididymis of the GD20 group. Apoptotic cells are pointed out by arrows. Negative control sections, processed without TdT buffer, showed no staining (insert in B). Scale bars represent $20 \mu \mathrm{m}$. Values represent the mean \pm SD number of TUNEL-positive germ cells per 100 epididymal duct sections. Significant differences from control values are denoted as ${ }^{*} p<0.05$ ( $n=3$ for each group).

quantitative image analysis in which the signal intensities were expressed as relative optical density of diaminobenzidine deposits (Figure 3P). Statistically significant differences $(p<0.05)$ were found only in the stromal cells of the cauda region of GD20, PD2, and PD90 groups. For details, see Figure 3P.

Using Western blot analysis bands at approximately 43 $\mathrm{kDa}$ were detected in epididymal samples of control and experimental groups (Figure 4A-C). Statistically significant changes in the $\mathrm{Cx} 43$ protein expression levels were demonstrated only in the cauda epididymis $(p<0.01)$ of GD20 and PD2 and $(p<0.05)$ of GD80 and PD90 groups what confirmed immunohistochemical findings, pointing out that flutamide treatment had a region-specific effect on Cx43 protein expression at adulthood.

\section{Qualitative and quantitative evaluation of AR localization and expression}

Several types of AR-immunopositive cells were found in the epididymides of flutamide-exposed boars and control boars (Figure 5A-O). In detail, strong to very strong, exclusively nuclear staining for AR was detected in both, principal cells and basal cells of the three regions of control epididymis (Figure 5A-C). After prenatal exposure, and, in a lesser extend after postnatal exposure to flutamide, the intensity of the staining was almost similar in the principal cells of the caput, slightly reduced in both epithelial cells of the corpus and cauda, and apparently reduced in the basal cells of the cauda region (Figure 5D-O). The staining was also significantly reduced in the stromal cells surrounding the epididymal duct. Qualitative analysis of immunoreactivity for AR (Figure $5 \mathrm{~A}-\mathrm{O}$ ) was confirmed by quantitative image analysis (Figure 5P). In flutamide-treated males statistically significant decrease in AR expression $(p<0.05)$ was found in the stromal cells of all three regions and in the principal cells of the corpus and cauda $(p<0.05)$. The AR expression was also distinctly reduced in the basal cells, however statistically significant differences $(p<0.05)$ were found mostly in the cauda, as it was noted for the principal cells. For details, see Figure 5P. No immunopositive signal for AR was found when the incubation was performed with omission of the primary antibody (insert in Figure 5A).

Changes in the AR protein expression levels following exposure to flutamide versus the controls were assessed 


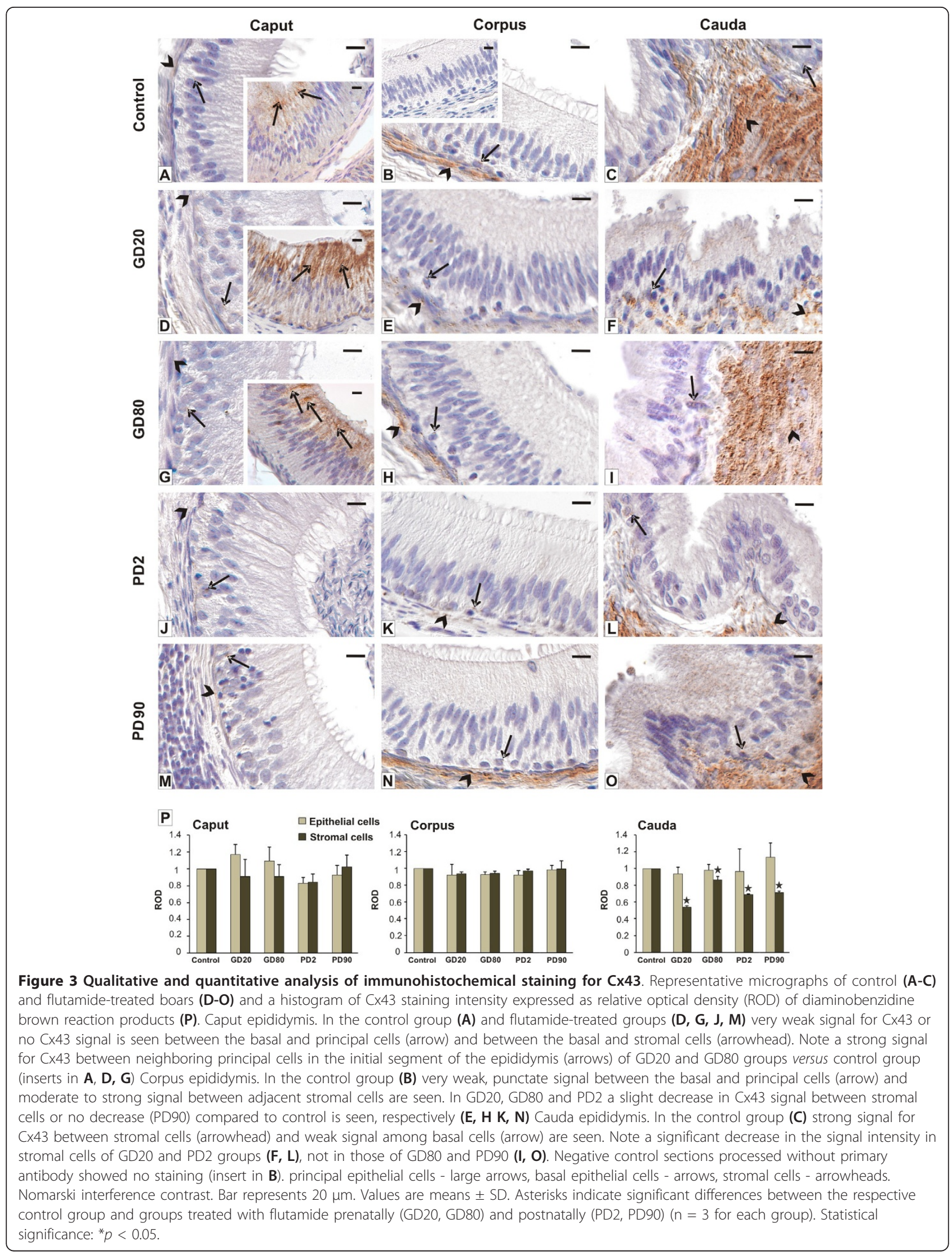



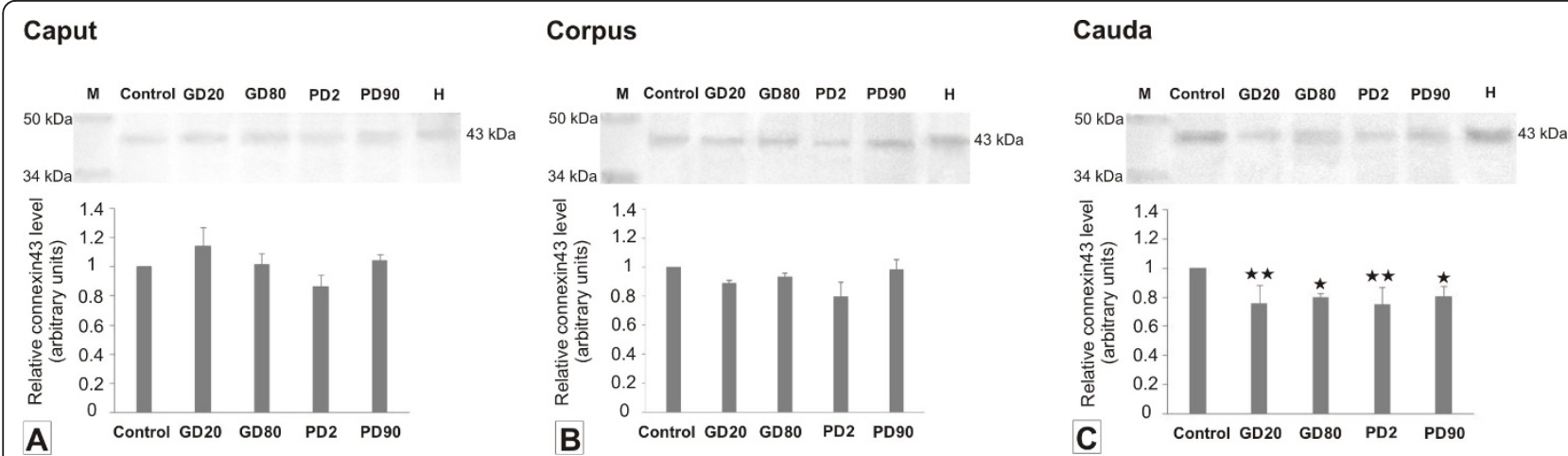

Figure 4 Western blot analysis of Cx43 protein expression levels in epididymides of control and flutamide-exposed boars. Representative Western blot shows a band at approximately $43 \mathrm{kDa}$ in epididymal samples of control and flutamide-treated groups (prenatal exposure - GD20, GD80; postnatal exposure - PD2, PD90). Lane H indicates pig heart used as the positive control. Lane M contains prestained protein standards; the molecular weights in $\mathrm{kDa}$ are indicated on the left. Relative Cx43 levels in the caput, corpus and cauda epididymides (A, B, C) expressed as arbitrary units. Data obtained from three separate analyses is expressed as mean $\pm S D$ ( $n=3$ for each group). Significant differences from control values are denoted as ${ }^{*} p<0.05,{ }^{* *} p<0.01$.

by Western blot analysis. As expected, a band at approximately $110 \mathrm{kDa}$ was detected in epididymal homogenates of control pigs. The presence of the AR protein was also found in tissue samples of GD20, GD80, PD2, and PD90 groups (Figure 6). No changes in the level of AR were noted in the caput epididymis irrespectively of the time of flutamide exposure when the data points were compared with the control group. In contrast, statistically significant decrease in the protein level was noted in the corpus region of GD20, PD2 and PD90 males $(p<0.01)$ and in the cauda of all groups receiving flutamide (Figure 6A-C). The above data point out that early gestational and postnatal flutamide treatment had a profound, likely region-specific effect on AR protein expression at adulthood.

\section{Discussion}

In the study herein we characterized alterations in the epididymis histology, changes in the number of apoptotic cells and changes in the expression of $\mathrm{Cx} 43$ and AR proteins in adult boar epididymis after prenatal and postnatal exposure to flutamide. The findings examining the long-term effects of flutamide on the mature epididymis provides new data on that reproductive organ and its function in the boar.

\section{Effect of flutamide on morphology of the boar epididymis}

Histological examination revealed decreased height of the epididymal epithelium in the corpus region, whereas the thickness of the stroma layer enlarged significantly in the cauda. Moreover, the caudal epididymal segment of GD20 and GD80 groups exhibited less folded appearance than that of control. These results are in line with the study by Smithwick and Young [32] who reported a decrease in epithelial height and loss of stereocilia in androgen-deprived epididymis of adult chimpanzee. Interestingly, in the cauda region of PD2 and PD90 groups we observed bubble-like vesicles of sloughed cytoplasmic membranes, likely derived from stereocilia, whereas in the caput of PD2 and PD90 groups agglomeration of leukocytes characteristic of an inflammation response to tissue damage were detected. Massive leukocyte infiltration in rat epididymis as associated with suppression of testosterone production has been reported by Atanassova et al. [33]. It is possible therefore that the increased number of leukocytes, as a consequence of flutamide action, is associated with their phagocytic role in the epididymis. The presence of spermatophages has earlier been reported in the stallion epididymis [34], while the occurrence of the intra-epithelial lymphocytic population has been demonstrated in human epididymis [35].

\section{Effect of flutamide on apoptotic cell death along the boar epididymis}

The results herein revealed a statistically significant increase $(p<0.05)$ in the number of apoptotic epithelial cells throughout the boar epididymis of GD20 group. After postnatal treatment a distinct increase in the number of TUNEL-positive cells was observed in the caput and cauda. These data indicate that the cell death could be activated by flutamide action. A region-specific difference of apoptosis in epididymis has also been observed after castration in rats [36]. It is well known that the caput epididymis requires higher androgen level to maintain its morphology and functions, thus it seems likely that more cells undergoing apoptosis might occur as a consequence of impaired androgen action. In accord, long-term apoptotic cell death process has been reported in adult rat germ cells exposed in utero to 

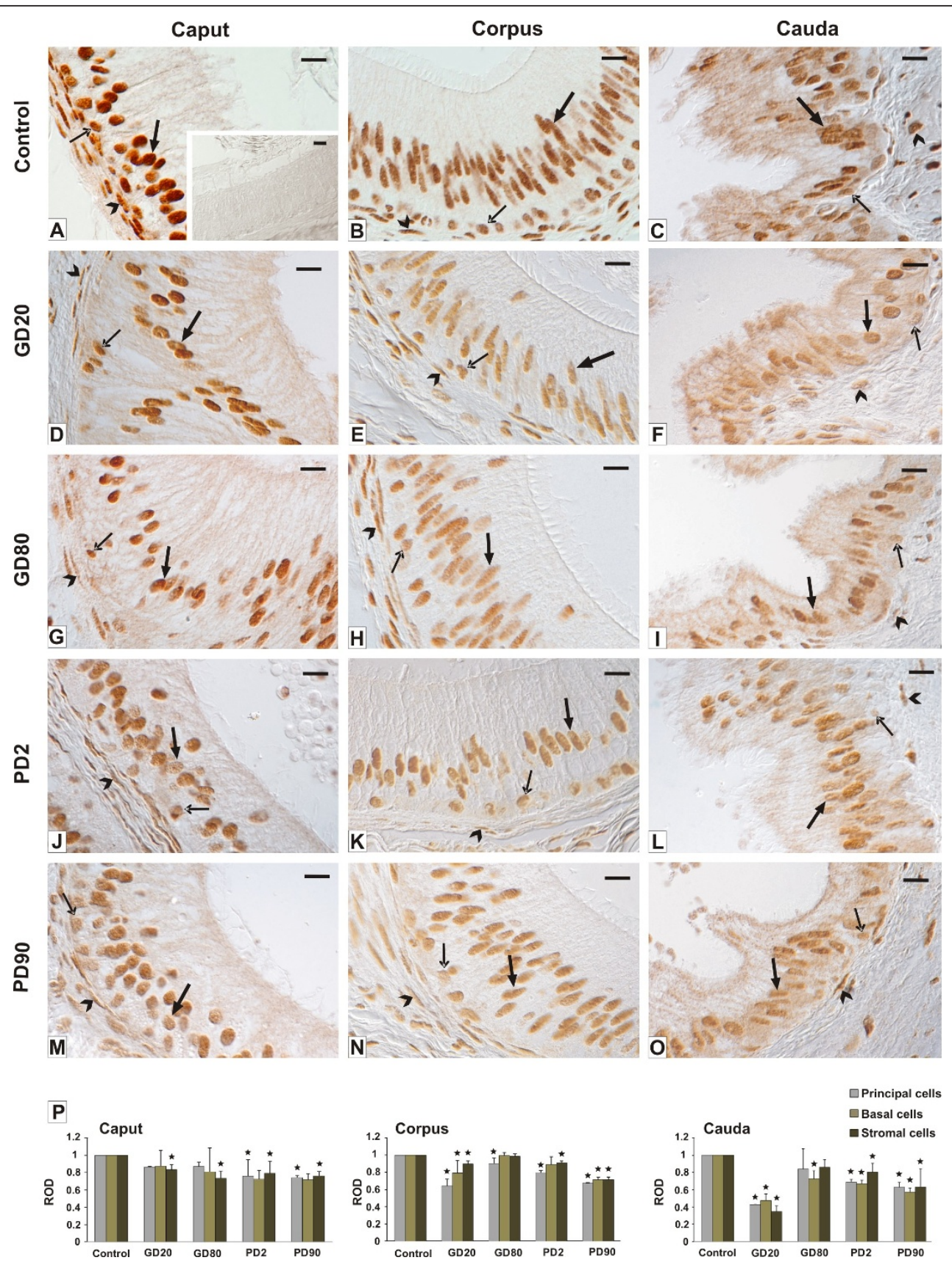

Figure 5 Qualitative and quantitative analysis of immunohistochemical staining for AR. Representative micrographs of control (A-C) and flutamide-treated boars (D-O) and a histogram of AR staining intensity expressed as relative optical density (ROD) of diaminobenzidine brown reaction products $(\mathbf{P})$. Caput epididymis. In the control group $(\mathbf{A})$ very strong intensity of AR staining is seen in the nuclei of principal cells (bold arrow), moderate to strong staining is seen in basal cells (arrow) and in stromal cells (arrowhead). In flutamide-treated males moderate to strong staining is seen in the nuclei of principal cells, weak staining is visible in basal cells and stromal cells $\mathbf{( D ,} \mathbf{G}, \mathbf{J}, \mathbf{M})$. Note a slight decrease in the staining intensity in principal and basal cells, while in stromal cells a marked decrease is seen (F, I, L, $\mathbf{O})$ Corpus epididymis. In the control group (B) strong intensity of AR staining in the nuclei of principal, basal, and stromal cells is seen. Note a marked decrease in the staining intensity in all cell types after flutamide-treatment $(\mathbf{E}, \mathbf{H}, \mathbf{K}, \mathbf{N})$ Cauda epididymis. In the control group $\mathbf{( C )}$ moderate to strong intensity of AR staining in the nuclei of principal and stromal cells and weak staining in basal cells is seen. Note a significant decrease in the staining intensity in principal and basal cells after flutamide exposure $(\mathbf{F}, \mathbf{I}, \mathbf{L}, \mathbf{O})$. In the control tissue section, no immunostaining for ARs is observed when the incubation was performed without the primary antibody (insert in A). principal epithelial cells - large arrows, basal epithelial cells - arrows, stromal cells arrowheads. Nomarski interference contrast. Scale bar represents $20 \mu \mathrm{m}$. Values are means \pm SD. Asterisks indicate significant differences between the respective control group and groups treated with flutamide prenatally (GD20, GD80) and postnatally (PD2, PD90) ( $n=3$ for each group). Statistical significance: ${ }^{*} p<0.05$. 


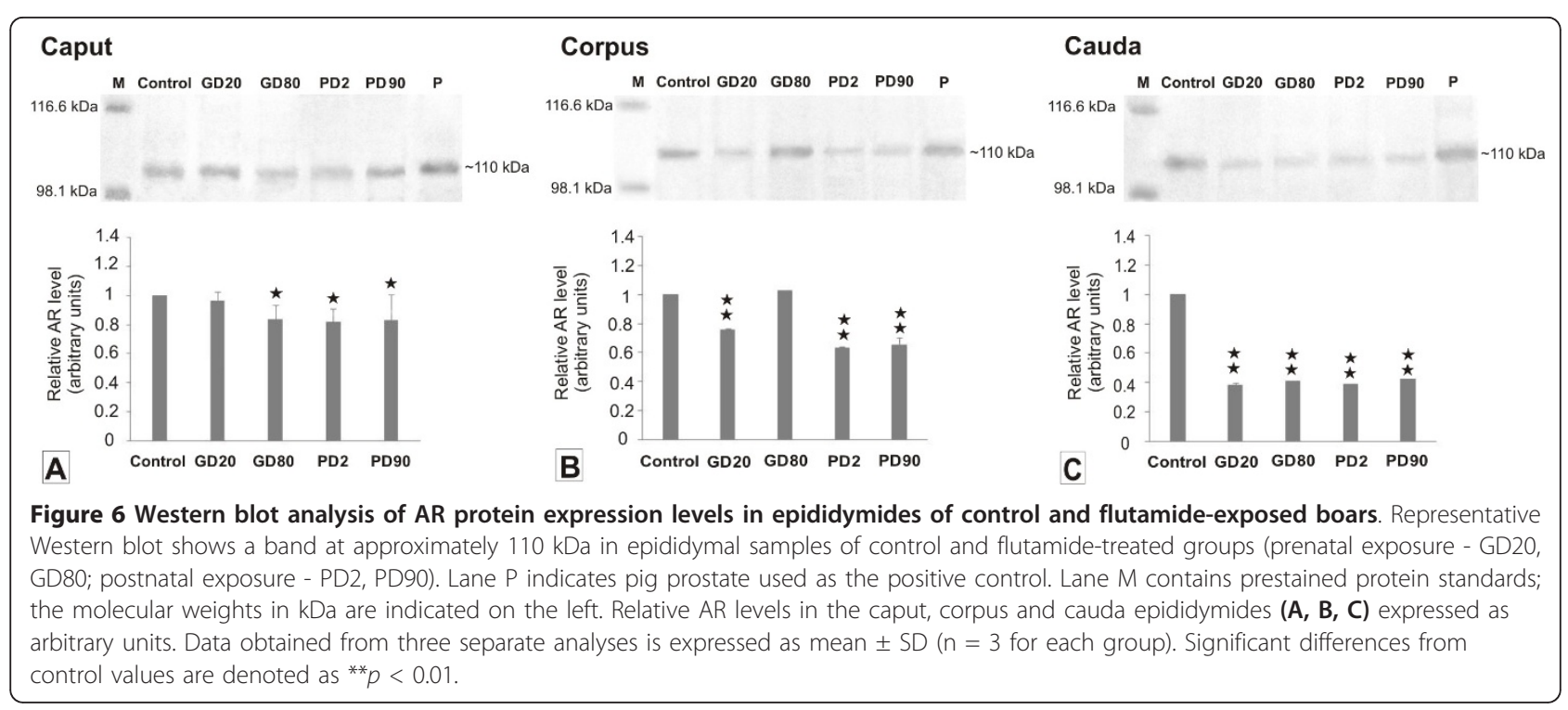

flutamide and vinclozolin [37,38]. According to McLachlan and co-workers [39] the resulting decrease in testosterone level and/or its action appears to be the primary cause for the negative effect on spermatogenesis. The above data allow the explanation for scarce spermatic content observed in the cauda epididymis of GD20, PD2, and PD90 groups. Moreover, inhibition of the sperm transition to the corpus epididymis was observed, probably as a result of a massive cell sloughing that formed intraluminal cell debris in the caput region of PD2 and PD90 groups. In contrast, acceleration of sperm transition through epididymis by androgen deprivation has been reported in rats exposed to several environmental contaminants [40]. It should be mentioned that any toxic insult to testicular Leydig cells causes androgen deprivation in rete testis fluid, which in consequence, can affect normal secretion of various proteins by epididymal cells. It is also likely that round cells observed in the lumen of flutamideexposed males may derive from the testes, since a drastic decrease in testicular germ cell population was observed as a consequence of flutamide action (unpublished data). Our results are in line with the study by O'Donnell and co-workers [41] who observed appearance of round spermatids detached from seminiferous epithelium as a result of testosterone withdrawal in the rat. A role of androgens along the epididymis in creating the microenvironment necessary for maturation and storage of spermatozoa has thoroughly been analyzed by Hinton and Palladino [42]. Thus, differential response to flutamide among the cells of the various segments of the boar epididymis supports the notion that the caput, corpus and cauda are not equally dependent on androgen.

\section{Effect of flutamide on AR and Cx43 expression along the boar epididimis}

After flutamide exposure we showed a positive staining for ARs (though of various intensity) in the principal and basal epithelial cells and in the stroma layer throughout the epididymis. This reflects the abundance of different cell types of the epididymis that are directly regulated by androgens. Whatever the cell type the staining was restricted to the cell nuclei and the pattern of the staining remained unchanged in flutamideexposed boars. In contrast, Trybek et al. [43] reported affected staining pattern in finasteride-treated rats; ARs were localized to the cytoplasm of epithelial epididymal cells. Moreover, we noted a significant decrease in the staining intensity in both epithelial cells of the corpus and cauda regions. On the other hand, lack of significant alterations in the AR protein level within the caput of flutamide-treated boars could be explained by too high androgen level in this region, which could not effectively be blocked by the flutamide. Turner et al. [44] reported that the total androgen level in the lumen of the caput epididymidis is 6-fold higher than that in the cauda epididymis. Furthermore, the intensity of the staining and the number of immunopositive cells in the stroma layer were reduced from the caput to cauda regions when compared to the controls. Also the relative AR level was significantly lower $(p<0.01)$ in the corpus and cauda segments of flutamide-exposed boars. This corroborates a study by Zhu et al. [45] who demonstrated a subsequent decline of AR levels in stromal cells after azaline treatment. It seems likely therefore that the stromal cells from the distal regions of the epididymis are more sensitive than those of the caput to flutamide action. Concomitantly, exposure to flutamide 
(GD20 and PD2) induced a significant decrease $(p<0.05)$ in $\mathrm{Cx} 43$ expression in the stromal cells of the corpus and cauda regions that corresponded with a distinct reduction $(p<0.01)$ of the relative $\mathrm{Cx} 43$ protein expression levels in the cauda. It gives rationale that early gestational exposure to flutamide and its neonatal administration have a profound, mostly segment-specific effect on the stromal cells. Abundant intercellular communication in the stroma may be important in expelling spermatozoa from the cauda epididymis at the time of ejaculation as previously suggested by Dufresne et al. [46]. Therefore, a significant reduction in the expression of $\mathrm{Cx} 43$ in these cells after flutamide treatment with concomitant lack of the signal in the stromal cells suggests flutamide as targeting Cx43 protein and affecting the process of epididymal microenvironment formations. On the other hand, abundant expression of $\mathrm{Cx} 43$ between the stromal cells of the control boar epididymis indicates the role of gap junctional communication in normal contraction of epididymal duct. It seems likely therefore that drastic decrease in the expression of $\mathrm{Cx} 43$ observed in the stromal cells after exposure to flutamide at GD20 and PD2 could be responsible for altered transit of spermatozoa from the corpus to cauda epididymis. This indicates that the expression of $\mathrm{Cx} 43$ protein in the stroma of adult pigs could be regulated, among other factors, by androgens. These results are in line with the study by the group of Cyr [47] who has proposed a crucial role for Cx43 to rat epididymal function. They showed altered Cx43 expression in orchidectomized rats what suggests that androgen may regulate the gap junction protein expression. In another study, Cyr and co-workers demonstrated that thyroid hormones preferentially regulate the connexin expression in proximal segments of the epididymis but not in the cauda region [48]. Interestingly, in GD20 and GD80 groups we observed a high expression of $\mathrm{Cx} 43$ protein between adjacent principal cells at their apical or lateral margins in the initial segment, not in the caput region. In the latter, small punctate binding sites for Cx43 were found only at the base of the epithelium. Such localization is consistent with that observed in the stallion and Egyptian water buffalo epididymides $[25,49]$, respectively. According to Cyr et al. [47] the regulation of $\mathrm{Cx} 43$ in the epithelium of the initial epididymal segment indicates that androgens regulate the targeting of Cx43 towards specific cell-to-cell interface. Based on recent studies, however, Pointis and co-workers [50] stated that the reason why androgens preferentially regulate connexin expression in different regions of the epididymis still remains unknown.

\section{Conclusions}

Concerning our results, it seems likely that the mechanisms that allow flutamide to interfere with numerous physiological processes by blocking androgen receptors are fully developed at adulthood. This seems to be in line with earlier studies on rats demonstrating the specificity of epididymal secretion as progressively established with age [51,52]. Flutamide, by blocking the androgen action, is responsible for an impairment of the microenvironment created by epididymal cells for sperm maturation and their storage. A decrease in AR protein levels results in altered androgen signaling which may cause disturbances in androgen-dependent processes including $\mathrm{Cx} 43$ (de)regulation, however, we can not exclude the possibility that in response to flutamide decreased Cx43 expression may represent one mechanism responsible for functional disturbance of the boar epididymis. Summing it up, the results indicate that early developmental window and the neonatal period of time are the most critical for flutamide-induced changes later in life of the boar.

\section{Acknowledgements and Funding}

We are grateful to Professor Marek Koziorowski and Dr. Anna TabeckaLonczynska (Department of Physiology and Reproduction of Animals, University of Rzeszow, Poland) for assistance with flutamide treatment and their kind donation of animals. This work was financially supported by the Academic Grant for Professors 2008, the "MISTRZ" Program from The Foundation for Polish Science (to B.B) and, in part, by the Ministry of Science and Higher Education, a grant N N303339835.

\section{Authors' contributions}

$M L$ carried out qualitative and quantitative immunochemistry, Western blotting and performed the statistical analysis; IK-S performed the TUNEL assay and helped to draft the manuscript; MK-B participated in the sequence alignment and analyzed data; KC and DZ (students) carried out histology and provided technical help; BB designed the study and drafted the manuscript. All authors read and approved the final manuscript.

\section{Authors' information}

The results reported herein are part of ML's PhD studies performed at the Jagiellonian University of Krakow for a doctor of philosophy degree.

\section{Competing interests}

The authors declare that they have no competing interests.

Received: 27 October 2010 Accepted: 22 February 2011 Published: 22 February 2011

\section{References}

1. Saez JC, Berthoud VM, Branes MC, Martinez AD, Bneyer EC: Plasma membrane channels formed by connexins: their regulation and functions. Physiol Rev 2003, 83:1359-1400.

2. Robaire B, Viger RS: Regulation of epididymal epithelial cell functions. Biol Reprod 1995, 52:226-236.

3. Cooper TG: Interactions between epididymal secretions and spermatozoa. J Reprod Fertil 1998, 53:119-136.

4. Jones RC: To store or mature spermatozoa? The primary role of the epididymis. Int J Androl 1999, 22:57-67.

5. Syntin P, Dacheux $J$, Dacheux F: Postnatal development and regulation of proteins secreted in the boar epididymis. Biol Reprod 1999, 61:1622-1635.

6. Friend DS, Gilula NB: Variations in tight and gap junctions in mammalian tissue. J Cell Biol 1972, 53:758-776.

7. Gye MC, Ohsako S: Effects of flutamide in the rat testis on the expression of occludin, an integral member of the tight junctions. Toxicol Lett 2003, 143:217-222 
8. Fiorini C, Tilloy-Ellul A, Chevalier S, Charuel C, Pointis G: Sertoli cell junctional proteins as early targets for different classes of reproductive toxicants. Reprod Toxicol 2004, 18:413-421.

9. Pujol A, Bayard F: Androgen receptor in the rat epididymis and their hormonal control. J Reprod Fertil 1979, 56:217-222.

10. Bedford JM: The status and the state of the human epididymis. Hum Reprod Update 1994, 9:2187-2199.

11. Pearl CA, Berger T, Roser JF: Estrogen and androgen receptor expression in relation to steroid concentrations in the adult boar epididymis. Domest Anim Endocrinol 2007, 33:451-459.

12. Goyal HO: Histoquantitative effects of orchiectomy with and without testosterone enanthate treatment on the bovine epididymis. Am J Vet Res 1983, 44:1085-1090

13. Blok LJ, Bartlett JM, Bolt-De Vries J, Themmen AP, Brinkmann AO, Weinbauer GF, Nieschlag E, Grootegoed JA: Effect of testosterone deprivation on expression of the androgen receptor in rat prostate, epididymis and testis. Int J Androl 1992, 15:182-198.

14. Goyal HO, Hutto V, Maloney MA: Effects of androgen deprivation in the goat epididymis. Acta Anat 1994, 150:127-135.

15. Kopera I, Tuz R, Hejmej A, Schwarz T, Koczanowski J, Bilinska B: Immunolocalization of androgen receptors in the boar epididymis: the effect of GnRH agonist deslorelin. Reprod Domest Anim 2009, 44:266-272.

16. Kolasa A, Marchlewicz M, Adler G, Ciechanowicz A, Glabowski W, Wiszniewska B: Expression of E-SOD, GPX5 mRNAs and immunoexpression of $\mathrm{Cu} / \mathrm{ZnSOD}$ In epithelial cells of finasteride-treated rats. Andrologia 2008, 40:303-311.

17. Ungefroren $H$, Ivell $R$, Egun $S$ : Region-specific expression of the androgen receptor in the human epididymis. Mol Hum Reprod 1997, 3:933-940.

18. Tekpetey FR, Amann RP: Regional and seasonal differences in concentrations of androgen and oestrogen receptors in ram epididymal tissue. Biol Reprod 1998, 58:1051-1060.

19. You L, Sar M: Androgen receptor expression in the testes and epididymides of prenatal and postnatal Spraque-Dawley rats. Endocrine 1998, 9:253-261.

20. Bilinska B, Hejmej A, Gancarczyk M, Sadowska J: Immunoexpression of androgen receptors in the reproductive tract of the stallion. Ann NY Acad Sci 2005, 1040:27-30.

21. Kopera I, Durlej M, Hejmej A, Knapczyk-Stwora K, Duda M, Koziorowski M, Slomczynska M, Bilinska B: Effects of pre- or postnatal exposure to flutamide on connexin 43 Expression in testes and ovaries of prepubertal pigs. Eur J Histochem 2010, 54:67-72.

22. Durlej M, Kopera I, Knapczyk-Stwora K, Hejmej A, Duda M, Koziorowski M, Slomczynska M, Bilinska B: Connexin 43 gene expression in male and female gonads of porcine offspring following in utero exposure to an anti-androgen flutamide. Acta Histochem 2011, 113:6-12.

23. Lunstra DD, Ford JJ, Christenson RK, Allrich RD: Changes in Leydig cell ultrastructure and function during pubertal development in the boar. Biol Reprod 1986, 34:145-158.

24. Hejmej A, Wiszniewska B, Kosiniak-Kamysz K, Sadowska J, Bilinska B: The presence of androgen receptors in the epididymis and prostate of the stallion and cryptorchid horse - a preliminary study. Vet J 2006, 171:373-379.

25. Hejmej A, Kotula-Balak M, Sadowska J, Bilinska B: Expression of connexin 43 protein in testes, epididymides, and prostates of stallions. Equine Vet $J$ 2007, 39:122-127.

26. Hejmej A, Kopera I, Kotula-Balak M, Gizejewski Z, Bilinska B: Age-dependent pattern of connexin43 expression in testes of European bison (Bison bonasus, L.). J Exp Zool 2009, 311A:667-675.

27. Smolen AJ: Image analytic techniques for quantification of immunocytochemical staining in the nervous system. In Methods in Neurosciences. Edited by: Conn PM. San Diego: Academic Press; 1993:208-229.

28. Hejmej A, Kotula-Balak M, Galas J, Bilinska B: Effects of 4-tert-octylphenol on the testes and seminal vesicles in adult bank voles. Reprod Toxicol 2011, 31:95-105.

29. Kotula-Balak M, Hejmej A, Sadowska J, Bilinska B: Connexin 43 expression in human and mouse testes with impaired spermatogenesis. Eur J Histochem 2007, 51:261-268.

30. Bradford MM: A rapid and sensitive method for the quantitation of microgram quantities of protein utilizing the principle of protein-dye binding. Anal Biochem 1976, 72:248-254.
31. Laemmli UK: Cleavage of structural proteins during the assembly of the head of bacteriophage T4. Nature 1970, 227:680-685.

32. Smithwick EB, Young G: Histological effects of androgen deprivation on the adult chimpanzee epididymis. Tissue Cell 2001, 33:450-461.

33. Atanassova N, McKinnell C, Fisher J, Sharpe RM: Neonatal treatment of rats with diethylstilboestrol (DES) induces stromal-epithelial abnormalities of the vas deferens and cauda epididymis in adulthood following delayed basal cell development. Reproduction 2005, 129:589-601.

34. Lopez ML, Bustos-Obregon E: Spermatophagy in the stallion epididymis: a scanning and transmission electron microscopy study. Acta Anat 1995, 153:181-188.

35. Yakirevich E, Yanai O, Sova Y, Sabo E, Stein A, Hiss J, Resnick MB: Cytotoxic phenotype of intra-epithelial lymphocytes in normal and cryptorchid human testicular excurrent ducts. Hum Reprod 2002, 17:275-283.

36. Fan X, Robaire B: Orchidectomy induces a wave of apoptotic cell death in the epididymis. Endocrinology 1998, 138:2128-2136.

37. Omezzine A, Chater S, Mauduit C, Florin A, Tabone E, Chuzel F, Bars R, Benahmed M: Long-term apoptotic cell death process with increased expression and activation of caspase- 3 and -6 in adult rat germ cells exposed in utero to flutamide. Endocrinology 2003, 144:648-661.

38. Anway MD, Rekow SS, Skinner MK: Comparative anti-androgenic actions of vinclozolin and flutamide on transgenerational adult onset disease and spermatogenesis. Reprod Toxicol 2008, 26:100-106.

39. McLachlan RI, Wreford NG, Tsonis C, De Kretser DM, Robertson DM: Testosterone effects on spermatogenesis in the gonadotropin-releasing hormone-immunized rat. Biol Reprod 1994, 50:271-280

40. Klinefelter GR, Suarez JD: Toxicant-induced acceleration of the epididymal sperm transit: androgen-dependent proteins may be involved. Reprod Toxicol 1997, 11:511-519.

41. O'Donnell L, McLachlan R, Wreford NG, de Kretser DM, Robertson DM: Testosterone withdrawal promotes stage-specific detachment of round spermatids from the rat seminiferous epithelium. Biol Reprod 1996, 55:895-901.

42. Hinton BT, Palladino MA: Epididymal epithelium: its contribution to the formation of a luminal fluid microenvironment. Microsc Res Tech 1995, 30:67-81.

43. Trybek G, Kolasa A, Marchlewicz M, Wenda-Rozewicka L, Wiszniewska B: Immunolocalization of androgen receptor in the epididymis of rats with dihydrotestosterone deficiency. Reprod Biol 2005, 3:291-301.

44. Turner TT, Jones CE, Howards SS, Ewing LL, Zegeye B, Gunsalus GL: On the androgen microenvironment of maturing spermatozoa. Endocrinology 1984, 115:1925-1932.

45. Zhu LJ, Hardy MP, Inigo IV, Huhtaniemi L, Bardin CW, Moo-Young AJ: Effects of androgen on androgen receptor expression in rat testicular and epididymal cells: a quantitative immunohistochemical study. Biol Reprod 2000, 63:368-376.

46. Dufresne J, Finnson KF, Gregory M, Cyr DG: Expression of multiple connexins in the rat epididymis indicates a comples regulation of gap junctional communication. Am J Physiol Cell Physiol 2003, 284:33-43.

47. Cyr DG, Hermo L, Laird DW: Immunocytochemical localization and regulation of connexin43 in the adult rat epidydymis. Endocrinology 1996, 137:1474-1485

48. St-Pierre N, Dufresne J, Rooney AA, Cyr DG: Neonatal hypothyroidism alters the localization of gap junctional protein connexin 43 in the testis and messenger RNA levels in the epididymis of the rat. Biol Reprod 2003, 68:1232-1240.

49. Alkafafy M, Elnasharty M, Sayed-Ahmed A, Abdrabou M: Immunohistochemical studies of the epididymal duct in Egyptian water buffalo (Bubalus bubalis). Acta Histochem 2011, 113:96-102.

50. Pointis G, Fiorini C, Defamine N, Segretain D: Gap junctional communication in the male reproductive system. Biochim Biophys Acta 2005, 1719:102-116.

51. Ueda H, Hirano T, Fujimoto S: Changes in protein secretory patterns during the development of the rat epididymis. Zool Sci 1990, 7:681-690.

52. Bendahmane $\mathrm{M}$, Abou-Haila A: Synthesis, characterization and hormonal regulation of epididymal proteins during postnatal development of the mouse. Differentiation 1994, 55:119-125.

doi:10.1186/1751-0147-53-12

Cite this article as: Lydka et al: Morphological and functional alterations in adult boar epididymis: Effects of prenatal and postnatal administration of flutamide. Acta Veterinaria Scandinavica 2011 53:12. 